\title{
BIOSSORÇÃO DO CORANTE TÊXTIL AZUL 5G UTILIZANDO O BAGAÇO DE MALTE
}

\author{
J. C. ZANETTE ${ }^{1}$, H. H. PIFFER ${ }^{1}$, P. T. JUCHEN ${ }^{1}$, M. T. VEIT ${ }^{1}$, G. C. GONÇALVES ${ }^{2}$, M. \\ R. F. KLEN ${ }^{1}$ \\ ${ }^{1}$ Universidade Estadual do Oeste do Paraná \\ 2 Universidade Tecnológica Federal do Paraná \\ E-mail para contato: jessica_zanette@hotmail.com
}

\begin{abstract}
RESUMO - O objetivo do trabalho é avaliar a aplicação do bagaço de malte como material adsorvente no processo de adsorção do corante comercial azul 5G. Nos experimentos investigou-se a influência do pré-tratamento químico do bagaço de malte na adsorção do corante e a influência da velocidade de agitação na cinética de adsorção. Em cada experimento, alíquotas foram retiradas e a concentração de corante em solução quantificada mediante a leitura da absorbância em espectrofotômetro. Os resultados obtidos demonstraram que o bagaço de malte, resíduo da indústria cervejeira, pode ser utilizado em lavanderias industriais na adsorção do corante azul $5 \mathrm{G}$ de forma eficiente.
\end{abstract}

\section{INTRODUÇÃO}

Segundo Alves (2013), apesar de o desenvolvimento industrial trazer avanços e benefícios para a humanidade, o aumento das atividades industriais tem tornado os problemas ambientais cada vez mais críticos e freqüentes.

$\mathrm{Na}$ indústria têxtil são utilizadas grandes quantidades de água e corantes em seus produtos finais, sendo que muitos desses corantes possuem moléculas de estrutura complexas, as quais são de difícil degradação. Além de alterar a coloração, a presença desses corantes nos efluentes afeta a solubilidade de gases nos corpos receptores e reduz a penetração da luz solar, diminuindo a capacidade de aeração dos corpos hídricos e, consequentemente, prejudicando o processo de fotossíntese (CARDOSO, 2012a).

Com o objetivo de diminuir os impactos ambientais, métodos de tratamento de efluentes têm sido desenvolvidos (LEAL et al., 2011). Porém, métodos químicos costumam utilizar altas dosagens de produtos e tornam-se economicamente inviáveis. Neste sentido, o processo de adsorção apresenta-se como um método alternativo no tratamento de efluentes contendo corantes (DAL PIVA et al., 2011).

A adsorção é uma técnica eficiente e de baixo custo, que pode empregar vários adsorventes (OLIVEIRA et al., 2014). Os biossorventes são em sua maioria, gerados de 
resíduos agrícolas, são substitutos do carvão ativado, adsorvente que, quando utilizado em grandes escalas, apresenta alto custo e dificuldades em sua regeneração. Resíduos sólidos da agroindústria, como o bagaço da cana de açúcar, mesocarpo de coco e serragens de madeira, estão disponíveis em grande quantidade e podem ser considerados adsorventes em potencial devido ao seu baixo custo por não receber nenhum tratamento prévio e por suas características físico-químicas (MATOS et al., 2013).

O bagaço de malte, também conhecido como borra de cervejaria ou bagaço de cerveja, é um dos resíduos da indústria cervejeira. Sendo o bagaço de malte um subproduto da indústria resultante do processo de fermentação ao qual são submetidos os grãos utilizados no processo de fabricação da cerveja (CARDOSO, 2012b). Nesse sentido, este trabalho teve como objetivo investigar o efeito do pré-tratamento químico do bagaço de malte e da velocidade de agitação na adsorção do corante azul reativo $5 \mathrm{G}$.

\section{MATERIAIS E MÉTODOS}

\subsection{Preparo do Material Adsorvente e da Solução de Corante}

O bagaço de malte utilizado para a realização dos experimentos foi cedido por uma indústria cervejeira localizada no Oeste do Paraná - Brasil. Primeiramente, lavou-se o bagaço de malte com água corrente, enxaguou-se com água destilada e então se secou o bagaço em uma estufa com circulação forçada de ar a temperatura de $70{ }^{\circ} \mathrm{C}$ por 48 horas.

Parte do bagaço de malte seco foi pré-tratado com solução de $\mathrm{HCl} 0,1 \mathrm{~mol} \mathrm{~L}^{-1}$ e outra parte com solução de $\mathrm{NaOH} 0,1 \mathrm{~mol} \mathrm{~L}^{-1}$ à temperatura ambiente. As soluções de prétratamento contendo o adsorvente foram mantidas sob agitação durante 24 horas, sendo posteriormente cada adsorvente tratado enxaguado sucessivas vezes com água destilada e seco a temperatura de $70{ }^{\circ} \mathrm{C}$ por 48 horas.

O corante utilizado foi o azul reativo $5 \mathrm{G}$ produzido pela Texpal Química. No preparo das soluções usou-se água destilada, de forma que, as concentrações de corante utilizadas nos experimentos foram obtidas a partir de uma solução estoque. Ajustou-se o pH das soluções de corante para atingir-se um pH 3, utilizando-se ácido clorídrico e hidróxido de sódio. Visando se determinar a concentração remanescente de corante, realizou-se a leitura das amostras por espectroscopia no ultravioleta visível (UV/Vis) no comprimento de onda de $610 \mathrm{~nm}$.

\subsection{Influência do Pré-tratamento Químico do Adsorvente na Adsorção}

O experimento de adsorção do corante reativo empregando o bagaço de malte in natura e pré-tratado foi realizado em duplicata em batelada, nas condições de $50 \mathrm{~mL}$ de solução de 


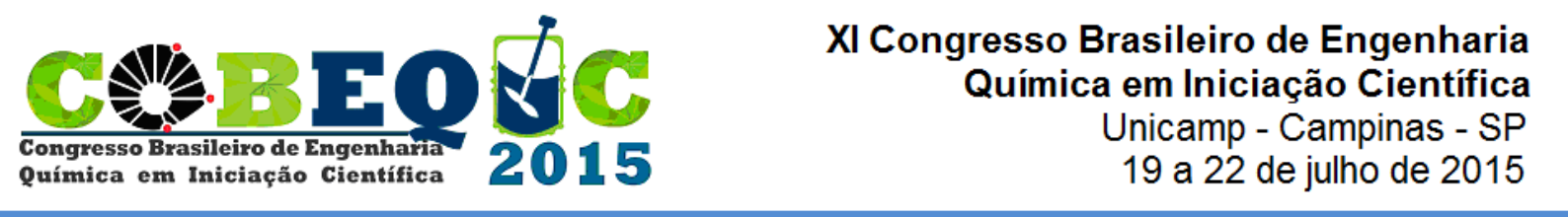

corante, concentração inicial de $175 \mathrm{mg} \mathrm{L}^{-1}$, pH 3, dosagem de adsorvente de $14 \mathrm{~g} \mathrm{~L}^{-1}$ base seca, temperatura controlada de $30^{\circ} \mathrm{C}$ e velocidades de agitação (shaker) de $100 \mathrm{rpm}$ por 24 horas. As amostras foram retiradas após 24 horas, quantificadas as concentrações de corante em $610 \mathrm{~nm}$ e a quantidade de corante adsorvido em equilíbrio $\left(\mathrm{q}_{\mathrm{eq}}\right)$, calculada empregando a Equação (1).

$$
q_{e q}=\frac{\left(C_{o}-C_{e q}\right) \cdot V}{m}
$$

Em que:

$\mathrm{C}_{0} \quad$ Concentração inicial de corante $\left(\mathrm{mg} \mathrm{L}^{-1}\right)$;

$\mathrm{C}_{\mathrm{eq}} \quad$ Concentração de equilíbrio remanescente de corante após 24 horas ( $\left.\mathrm{mg} \mathrm{L}^{-1}\right)$;

$\mathrm{q}_{\mathrm{eq}} \quad$ Quantidade adsorvida de corante em equilíbrio após 24 horas ( $\left.\mathrm{mg} \mathrm{g}^{-1}\right)$;

$\mathrm{m} \quad$ Massa de adsorvente $(\mathrm{g})$, base seca;

V Volume da solução de corante em contato com o adsorvente (L).

\subsection{Influência da Velocidade de Agitação na Cinética de Adsorção}

Os experimentos de cinética de adsorção do corante foram realizados em duplicata nas seguintes condições: $50 \mathrm{~mL}$ de solução de corante azul 5G com a concentração inicial de 175 mg L-1, utilizando-se a dosagem de $14 \mathrm{~g} \mathrm{~L}^{-1}$ de adsorvente (base seca) previamente pré-tratado com a solução de $\mathrm{HCl} 0,1 \mathrm{~mol} \mathrm{~L}^{-1}$, temperatura controlada de $30{ }^{\circ} \mathrm{C}$ e de velocidades de agitação (shaker) de 70 e 100 rpm (durante 24 horas).

Amostras foram coletadas em intervalos de tempo pré-estabelecidos, quantificada a concentração de corante remanescente em solução e, a quantidade de corante adsorvido $(q(t))$ para cada tempo, calculada empregando a Equação (2).

$$
q(t)=\frac{\left(C_{o}-C(t)\right) \cdot V}{m}
$$

Em que:

$\mathrm{C}(\mathrm{t}) \quad$ Concentração remanescente de corante no tempo $(\mathrm{t})\left(\mathrm{mg} \mathrm{L}^{-1}\right)$;

$\mathrm{q}(\mathrm{t})$ Quantidade adsorvida de corante no tempo $(\mathrm{t})\left(\mathrm{mg} \mathrm{g}^{-1}\right)$.

\section{RESULTADOS E DISCUSSÃO}

O efeito do pré-tratamento do adsorvente bagaço de malte na adsorção do corante azul 5G está representado na Figura 1. 
Figura 1 - Quantidade de corante removida pelo bagaço de malte in natura e pré-tratado com as soluções de $\mathrm{HCl} 0,1 \mathrm{~mol} \mathrm{~L}^{-1} \mathrm{e} \mathrm{NaOH} 0,1 \mathrm{~mol} \mathrm{~L}^{-1}$

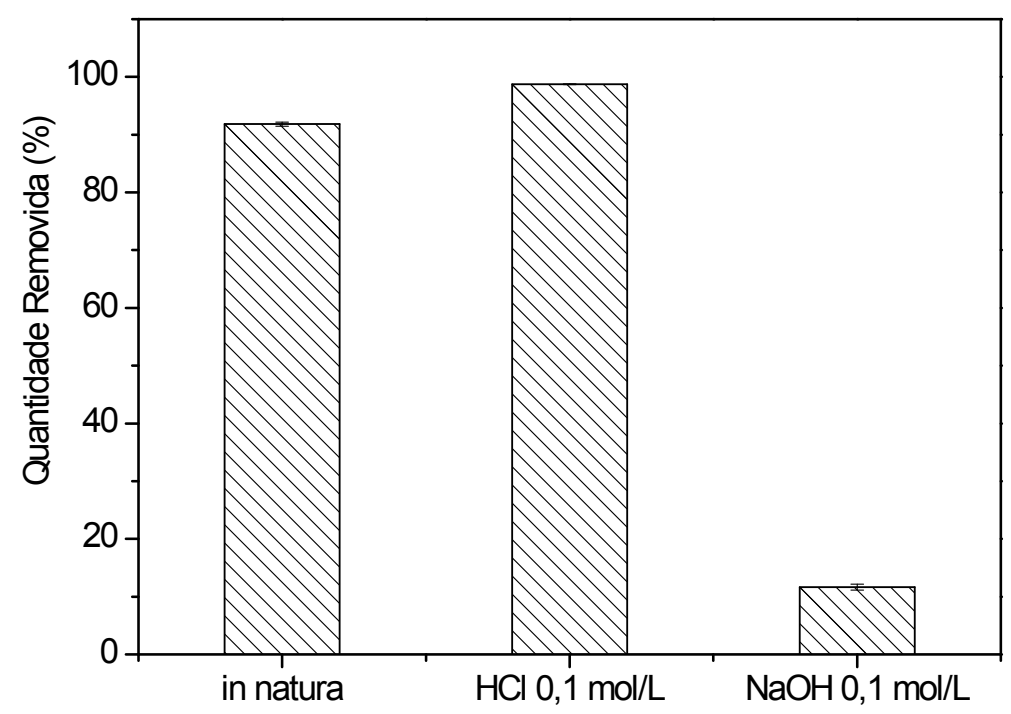

Observa-se na Figura 1 que o pré-tratamento químico da biomassa influenciou na quantidade de corante removida da solução. Essa remoção foi de 98,72\%, que corresponde a um $\mathrm{q}_{\mathrm{eq}}$ de $12,32 \mathrm{mg} \mathrm{g}^{-1}$ quando o bagaço de malte foi pré-tratado com a solução de $\mathrm{HCl}$, contra apenas $11,65 \%\left(\mathrm{q}_{\mathrm{eq}}=1,46 \mathrm{mg} \mathrm{g}^{-1}\right)$ se pré-tratado com a solução de $\mathrm{NaOH}$. Comparando-se estes resultados ao do bagaço de malte in natura $\left(\mathrm{C}_{0}=200 \mathrm{mg} \mathrm{L}^{-1}, \mathrm{pH} 3\right.$, dosagem de adsorvente de $14 \mathrm{~g} \mathrm{~L}^{-1}$ base seca, temperatura $=30{ }^{\circ} \mathrm{C}$ e velocidades de agitação=100 rpm) que obteve $\mathrm{q}_{\mathrm{eq}}$ de $13,85 \mathrm{mg} \mathrm{g}^{-1}$ equivalente a remoção de $91,8 \%$, se percebe um aumento na capacidade de adsorção quando utilizada a biomassa pré-tratada com solução de $\mathrm{HCl}$.

Assim, para os ensaios cinéticos de adsorção do corante azul $5 \mathrm{G}$ foi utilizado o bagaço de malte pré-tratado com a solução de $\mathrm{HCl} 0,1 \mathrm{~mol} \mathrm{~L}^{-1}$, nas rotações de 70 e $100 \mathrm{rpm}$, apresentadas na Figura 2.

Figura 2 - Cinética de adsorção do corante $5 \mathrm{G}$ pelo bagaço de malte nas rotações de 70 e $100 \mathrm{rpm}$

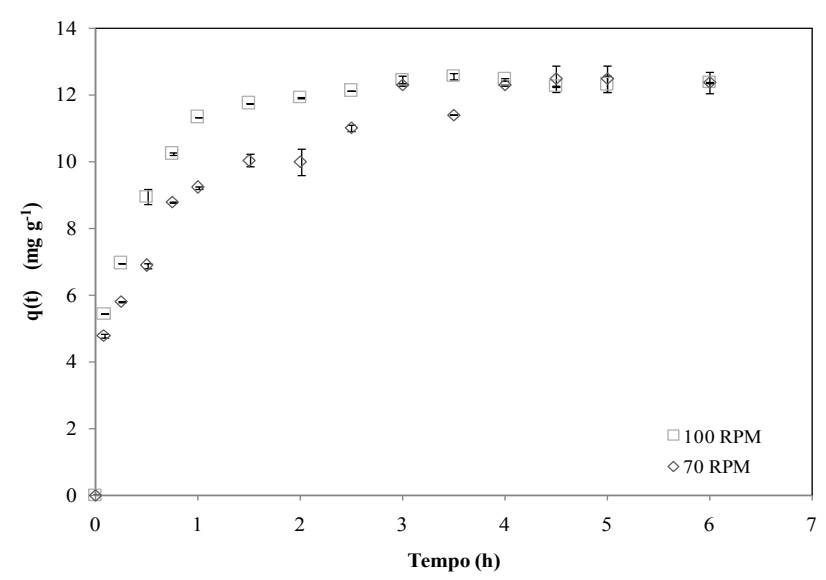


$\mathrm{Na}$ Figura 1 pode-se observar que a quantidade de corante removida pelo bagaço de malte pré-tratado foi mais rápida quando a velocidade de agitação foi de $100 \mathrm{rpm}$, fato que pode ser atribuído a baixa velocidade de agitação $(70 \mathrm{rpm})$ requerer um maior tempo de contato para o sistema atingir o equilíbrio.

A adsorção do corante reativo azul $5 \mathrm{G}$ pelo bagaço de malte pré-tratado ocorreu de forma mais acentuada nos primeiros 30 minutos, com 74,8\% $\left(\mathrm{q}(\mathrm{t})=8,9 \mathrm{mg} \mathrm{g}^{-1}\right)$ e $56 \%(\mathrm{q}(\mathrm{t})=$ $6,9 \mathrm{mg}$ g-1) de remoção nas velocidades de 100 e $70 \mathrm{rpm}$, respectivamente. O tempo de equilíbrio do sistema estabeleceu-se em torno de 3 horas para a velocidade de $100 \mathrm{rpm}$ com uma remoção de $12,46 \mathrm{mg} \mathrm{g}^{-1} \mathrm{e}$ de 4 horas para a velocidade de $70 \mathrm{rpm}\left(12,28 \mathrm{mg} \mathrm{g}^{-1}\right)$.

PANIAGUA et al. (2009) realizou ensaios de adsorção em batelada de Cloreto de Cetilpiridinio (CCP) em uma concentração de $0,54 \mathrm{mmol} / \mathrm{L}$ em um volume de $50 \mathrm{~mL}$, a $25^{\circ} \mathrm{C}$, massa de adsorvente (serragem e argila) fixa em 2,0 g, o tempo de contato igual a 20 minutos, variando a velocidade de agitação de 10 até $90 \mathrm{rpm}$. O autor verificou que o aumento da velocidade de agitação aumentava a quantidade removida de CCP.

Assim, verifica-se que o aumento da velocidade de agitação maximizou a taxa de transferência de massa do corante azul $5 \mathrm{G}$ até as partículas de bagaço de malte. Isso ocorre devido à maiores velocidades de agitação diminuírem a resistência a transferência de massa que ocorre na camada limite do adsorvente.

O bagaço de malte sem qualquer pré-tratamento também foi avaliado como material adsorvente do corante ácido Laranja 7 por SILVA et al. (2004a,b), os quais obtiveram uma adsorção máxima do corante ácido de $30,5 \mathrm{mg} \mathrm{g}^{-1}$ de bagaço de malte para um tempo de contato de 1 hora. Quando o adsorvente foi pré-tratado com solução de ácido sulfúrico $0,13 \mathrm{~mol} \mathrm{~L}^{-1}$, os autores verificaram que, a hidrólise da biomassa com ácido não aumentava capacidade de remoção do corante Laranja 7 (26 mg g-1). Os resultados foram obtidos pelos autores utilizando $\mathrm{pH}$ da solução de corante 4,5 e temperatura de $30^{\circ} \mathrm{C}$, não sendo informada a velocidade de agitação.

Pode-se verificar que o pré-tratamento do bagaço de malte com ácido não se mostrou viável para a adsorção do corante ácido Laranja 7, mas no caso do corante reativo Azul 5G houve uma melhora significativa da capacidade de adsorção da biomassa.

\section{CONCLUSÃO}

De acordo com o trabalho realizado, nas condições em que foi desenvolvido observouse que o pré-tratamento químico do adsorvente com solução de $\mathrm{HCl}$ aumentou seu poder adsortivo comparado com a utilização do bagaço de malte in natura. O equilíbrio do sistema foi estabelecido em 3 horas de contato biossorvente/corante na velocidade de agitação de 100 rpm. Assim, verificou-se que o bagaço de malte pode ser utilizado como material adsorvente de solução de corante azul reativo $5 \mathrm{G}$ com grande eficiência, sendo essa uma ótima maneira de reutilizar um resíduo de processo e diminuir os impactos ambientais. 


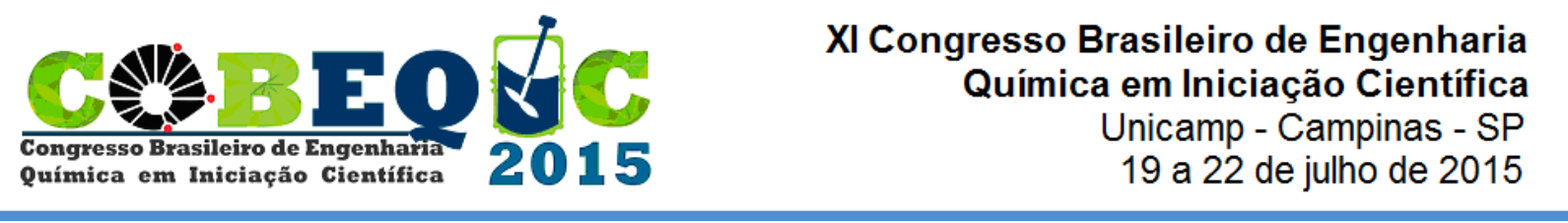

\section{REFERÊNCIAS}

ALVES, F.C. Estudo dos processos de adsorção utilizando argilas como adsorventes para remoção do corante verde malaquita. Dissertação de mestrado - Universidade Federal de Lavras. Lavras - MG, 2013.

CARDOSO, F. F. Propriedades de adsorção de água em farinhas mistas de arroz e bagaço de cevada pré-gelatinizadas por extrusão termoplástica. Dissertação de Mestrado. Universidade Estadual de Goiás, 2012a.

CARDOSO, N. F. Adsorção de corantes têxteis utilizando biossorventes alternativos. Tese de Doutorado. Universidade Federal do Rio Grande do Sul, 2012b.

DAL PIVA, J. A. L.; SANTOS, O.; ANDRADE, M. G. Determinação e análise de isotermas de adsorção do corante azul $5 \mathrm{G}$ em leito fixo de carvão ativado. Acta Scientiarum Technology. Maringá, v. 33, n. 4, p. 435-438, 2011.

LEAL, P. V. B.; ANJOS, J. P.; MAGRIOTIS, Z. M. Estudo da adsorção do corante azul de metileno em caulinita rosa. Journal of Biotechnology and Biodiversity, v. 2, pp. 38-42, August 2011.

MATOS, T. T. S.; JESUS, A. M. D.; ARAÚJO, B. R.; ROMÃO, L. P. C.; SANTOS, L. O.; SANTOSA, J. M. Aplicação de Subprodutos Industriais na Remoção de Corantes Reativos Têxteis. Revista Virtual Química, v.5, pp. 840-852, 2013.

OLIVEIRA, L. H.; ARRAES, D. D.; GOMES, G. E.; LIMA, A. E. O.; RAMOS, P. H. Estudo da adsorção do corante rodamina $\mathrm{B}$ em argila natural. $10^{\circ}$ Encontro Brasileiro de Adsorção. Guarujá -SP, 2014.

PANIAGUA, C. E. S.; LACERDA, N. M.; PIRES, K. A. D.; AMORIN, E. Estudo comparativo da influência da velocidade de agitação entre a serragem Gochnatia Polymorpha e o material argiloso. 33 ${ }^{a}$ Reunião Anual da Sociedade Brasileira de Química. Águas de Lindóia-SP, 2009.

SILVA, J.P.; SOUSA, S.; RODRIGUES, J.; ANTUNES, H.; PORTER, J.J.; GONÇALVES, I.; FERREIRA-DIAS, S. Adsorption of acid orange 7 dye in aqueous solutions by spent brewery grains. Separation and Purification Technology, v. 40, p.309-315, 2004a.

SILVA, J.P.; SOUSA, S.; GONÇALVES, I.; PORTER, J.J.; FERREIRA-DIAS, S. Modeling adsorption of acid orange 7 dye in aqueous solutions to spent brewery grains. Separation and Purification Technology, v. 40, p.163-170, 2004b.

WON, S.W.; CHOI, S.B.; YUN, Y.S. Interaction between protonated waste biomass of Corynebacterium glutamicum and anionic dye Reactive Red 4. Colloids and Surfaces A: Physicochemical Engineering Aspects, v.80, 2005. 